ISI Impact Factor

(2019-20): 1.628

IC Value (2019): 90.81

$\operatorname{SJIF}(2020)=7.893$

(c) (i) (3)

Copyright@IJCRR

\section{$\nabla$ \\ IJCRR \\ Section: Healthcare \\ Massive Myocardial Infarction Due to Acute Left Main Coronary Artery Occlusion in a Young Organophosphorus Poisoning: Case Report}

\section{Gautam Archana1, Patil Vijaysinh2, Rayannavar Nikhilesh³, Goel Himalaya ${ }^{4}$ Bhaleghare Sakshi ${ }^{5}$, Bammidi Rohit ${ }^{6}$}

'Head of the Department of Critical Care Unit, Krishna Institute of Medical Sciences, Karad, Maharashtra, India; 'Interventional Cardiologist, Krishna Institute of Medical Sciences, Karad, Maharashtra, India; ${ }^{34,5,6}$ ]unior residents, Department of Internal Medicine, Krishna Institute of Medical Sciences, Karad, Maharashtra, India.

\title{
ABSTRACT
}

Introduction: In the farmlands what has been found to be a common chemical for suicidal attempts are Organophosphate poison. This is common in many of the countries. Organophosphate poison is quite dangerous and can have impact once someone consume. Even the smell of this liquid or touch of the chemical to the skin can have a very harmful effect. Fatal left main carotid artery occlusion is rarely reported in literature.

Aim: To study the case of consumption of Chlorpyriphos- cypermethrin combination

Case Report: In the present paper we have reported a specific case of a person whose age was 25 years and who consumed a Chlorpyriphos- cypermethrin combination who later developed massive myocardial infarction with an ST-elevation $>12 \mathrm{~mm}$ in aVR followed by a cardiac arrest.

Discussion: Cardiac abnormalities are rare in organophosphorus compound poisoning. The patients have include arrhythmia, heart failure, cardiogenic shock, and sudden death. In those patients, clinical manifestations of damage caused by organophosphorus pesticides to the myocardium vary.

Conclusion: During the management of organophosphorus compound poisoning, intensive cardiac monitoring should be considered.

Key Words: Massive Myocardial Infarction, Acute LMCA Occlusion, Organophosphorous, Poisoning, Cardiac, Pyrethroid compound, Cypermethrin

\section{INTRODUCTION}

There are many types of inhibitors available, one of them are Organophosphate, it is potent cholinesterase inhibitors, which is capable of causing severe cholinergic toxicity following cutaneous exposure, inhalation or ingestion. ${ }^{1}$ Chlorpyriphos is a pesticide that contains a broad-spectrum chlorinated organophosphate. ${ }^{2}$ We use that to control many kinds of pests, termites, mosquitoes and roundworms. According to world health organization Chlorpyrifos is considered moderately hazardous on the base of acute toxicity. Exposure surpassing recommended levels has been linked to neurological effects, persistent developmental disorders, and autoimmune disorders. The symptoms of sever poisoning is seizures, unconsciousness, paralysis and suffocation from lung failure. ${ }^{3}$ A pyrethroid compound Cypermethrin widely used as an insecticide, is moderately toxic but excessive exposure can cause nausea, headache, muscle weakness, salivation, shortness of breath and seizures. Apart from the drug toxicity, these compounds cause many cardiac complications like QT prolongation, conduction blocks, arrhythmia. But rarely do they cause myocardial infarction.

\section{CASE REPORT}

A male who is 25 years old was admitted to the intensive care unit with of alleged history of intentional consumption of HAMLA (Chlorpyriphos 50\% + Cypermethrin5\%) around $50 \mathrm{ml}$ followed by 3 episodes of vomiting. The patient was

\section{Corresponding Author:}

Archana Gautam, Head of the Department of Critical Care Unit, Krishna Institute of Medical Sciences, Karad, Maharashtra, India. Email: drgautamarchaana@outlook.com

ISSN: 2231-2196 (Print) ISSN: 0975-5241 (Online)

Received: 17.02 .2021

Revised: 05.04 .2021

Accepted: 18.05 .2021

Published: 24.10 .2021 
brought to the hospital within 3-4 hours of consumption. On examination he was drowsy, sweating profusely with GCS of 6 (E1 V2 M3), pupils were constricted $<2 \mathrm{~mm}$ and neck holding was absent. Peradeniya organophosphate score was 7 , suggestive of moderate poisoning. Vitals at the time of admission were was-PR-60/min; BP-110/70 mmHg, RR32/min; SPO2- 92\%. Patient had no comorbid conditions. The patient was immediately taken on mechanical ventilation (ventriculocoronary arterial communication) VCAC mode and was treated with atropine, Pralidoxime and other supportive measures (IV fluids, gastric lavage, savlon body wash, and activated charcoal). Arterial blood gas analysis suggested metabolic acidosis with compensatory respiratory alkalosis and the blood analysis revealed a serum cholinesterase level of $1858 \mathrm{IU} / \mathrm{L}$ with serum CPK NAC level of $229 \mathrm{IU} / \mathrm{L}$. ECG at the time of admission had sinus rhythm with a heart rate of $\sim 68 / \mathrm{min}$. For the next 3 days, the patient was kept on mechanical ventilation under mild sedation with RASS of -2 (Richmond Agitation-Sedation Scale) and heart rate was maintained at $\sim 100 / \mathrm{min}$ on atropine at $0.2 \mathrm{mg} /$ hr. Inj. Heparin 5000 IU I.V 12 hourly was started as DVT prophylaxis on day 3. On day 4 around 10.30 P.M, the patient developed sweating and sinus tachycardia with a heart rate of 140/min lasting for 3-4 hours. Sudden ECGchanges were noticed in the cardiac monitor and the ECG recorded suggested acute left main coronary artery occlusion with deep ST depression $>10 \mathrm{~mm}$ in anterior and inferior leads and ST-elevation around $12 \mathrm{~mm}$ in aVR. Sooner he developed cardiac arrest and could not be revived by CPR and inotropic supports. Biochemical cardiac markers sent at that time were positive with Serum Trop I of $3.5 \mathrm{ng} / \mathrm{ml}$.

Table 1: Laboratory parameters

\begin{tabular}{|c|c|c|c|c|c|}
\hline Day & 1 & 2 & 3 & 4 & 5 \\
\hline $\mathrm{Hb}(\mathrm{g} / \mathrm{dl})$ & 16.5 & & & & 13.7 \\
\hline Total count $(/ \mu \mathrm{l})$ & 8500 & & & & 4600 \\
\hline $\begin{array}{l}\text { Platelet } \\
(\text { lakh/mm²) }\end{array}$ & 2.40 & & & & 1.50 \\
\hline IN & 1.0 & & & & \\
\hline Urea (mg/dl) & 20 & & 24 & & 23 \\
\hline Creatinine(mg/dl) & 1.0 & & 1.0 & & 1.1 \\
\hline Sodium (mEq/l) & 142 & & 142 & & 139 \\
\hline $\begin{array}{l}\text { Potassium } \\
(\mathrm{mEq} / \mathrm{l})\end{array}$ & $3 \cdot 3$ & & 3.0 & & 3.2 \\
\hline $\begin{array}{l}\text { Serum troponin } \\
(\mathrm{ng} / \mathrm{ml})\end{array}$ & & & & & $3 \cdot 5$ \\
\hline $\begin{array}{l}\text { Serum } \\
\text { cholinesterase }\end{array}$ & 1858 & & 1246 & & 1155 \\
\hline CPK NAC & 229 & & 1481 & & $>1000$ \\
\hline
\end{tabular}

\begin{tabular}{|c|c|c|c|c|c|c|}
\hline Day & & 1 & 2 & 3 & 4 & 5 \\
\hline \multirow[t]{5}{*}{ ABG } & $\mathrm{PH}$ & $7 \cdot 31$ & $7 \cdot 38$ & $7 \cdot 45$ & 7.49 & \\
\hline & $\mathrm{pO}_{2}$ & 86.0 & 81.9 & 405 & 113 & \\
\hline & $\mathrm{HCO}_{3}$ & 18.2 & 21.0 & 22.4 & 27.2 & \\
\hline & $\mathrm{pCO}_{2}$ & 35.1 & 33.7 & 29.6 & 33.5 & \\
\hline & Lactate & 6.1 & 3.0 & 0.7 & 0.5 & \\
\hline \multicolumn{2}{|c|}{ Urine routine, LFT } & \multicolumn{5}{|c|}{ Normal } \\
\hline
\end{tabular}

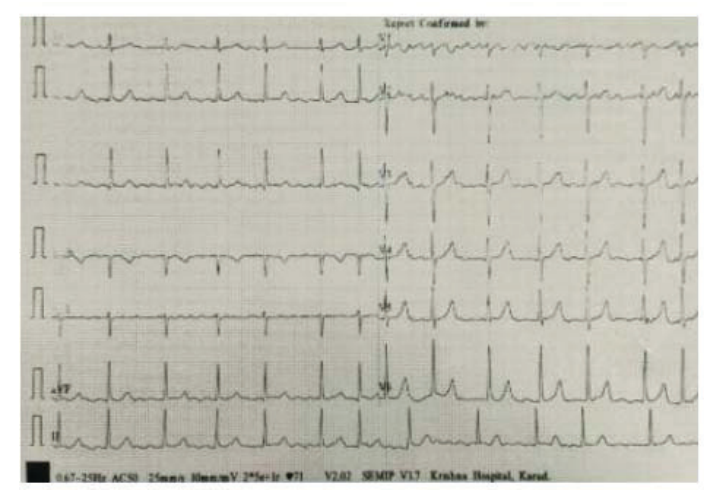

Figure 1: ECG on admission. Sinus rhythm with heart rate 68/ $\min$.

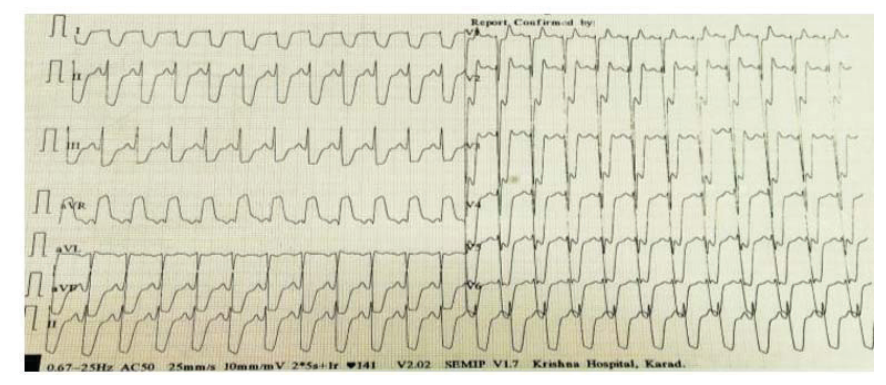

Figure 2: ECG on day 4. Sinus tachycardia with heart rate $140 / \mathrm{min}$ ST elevation in aVR $>12 \mathrm{~mm}$, ST depression in I, II, III, aVF, $\mathrm{V}_{2}$ to $\mathrm{V}_{6}>10 \mathrm{~mm}$.

\section{DISCUSSION}

Cardiac abnormalities are rare in organophosphorus compound poisoning. The patients have to include arrhythmia, heart failure, cardiogenic shock, and sudden death. In those patients, clinical manifestations of damage caused by organophosphorus pesticides to the myocardium vary. Myocardial injuries and myocardial infection are rarely reported, which cause by organophosphorus poisoning.

According to a study conducted by Aktar S et al. in 2019 on the complications of Organophosphorus poisoning, out of 100 cases, 29 had cardiac complications like premature ventricular contractions, prolonged QT, conduction block, 
polymorphic VT, Torsade de Pointes, sinus bradycardia which occurred during early hours of acute poisoning. ${ }^{1}$ But none of them had myocardial infarction as a complication in their study. For the development of these complications Hypoxia, electrolyte imbalance and acidosis is very important. Our case did not have any predisposing factors and never developed these complications. (Though metabolic acidosis was present when the admission is going on, it was corrected immediately).

According to a report of a case by P Joshi et al. on a 40-yearold patient with parathion consumption, it was found that patient had sinus bradycardia on admission. On the second day, the patient developed ST-segment elevation with T inversion in V3-V6 with Trop I of 3ng/ml. The patient was treated with antiplatelet, nitrates, LMWH and was discharged with the resolution of ST and T changes. ${ }^{2}$ In contrast to this, our case was a young male with no previous comorbidities who developed Massive myocardial infarction on day 4 with ECG showing ST elevation $>12 \mathrm{~mm}$ in aVR and ST depression in other leads $>10 \mathrm{~mm}$, with serum Trop I of $3.5 \mathrm{ng} / \mathrm{ml}$ indicating blockade in LMCA territory. ${ }^{3}$ Later he had a cardiac arrest and could not be revived.

The mechanism of cardiotoxicity by these compounds is not completely understood.

There are few postulations by which OP compounds can cause cardiac toxicity. ${ }^{4,5}$

1. Brief period of increased sympathetic tone.

2. Prolonged period of parasympathetic activity

3. QT prolongation followed by torsades de pointes. And also, other mechanism includes sympathetic/parasympathetic overactivity, hypoxia, dyselectrolemia and direct toxicity. Coronary vasospasm can also lead to myocardial infarction. Coronary vasospasm was caused by intracoronary injection of acetylcholine in individuals as demonstrated in a study conducted by Hario et al. and Yasue et al.. ${ }^{6,7}$

In a person with previous coronary artery plaque, the release of vasoactive amines like histamines and catecholamines leads to penetration of collagen matrix of plaque-causing erosion and rupture causing myocardial infarction. ${ }^{8}$ Release of inflammatory cytokines like histamines, neutral proteases, platelet-activating factors, arachidonic acid products, chemokines causes vasospastic angina, nonvasospastic angina, myocardial infarction known as Kounis phenomenon. ${ }^{9}$

Serious cardiac complications cause by Patchy myocardial involvement as a result of direct cardiac toxicity. ${ }^{10,11}$ Myocardial may not be manifest clinically or on echocardiography because it is involved in patchy. Continuous cardiac monitoring should be undertaken to detect dynamic cardiac changes Continuous cardiac monitoring should be undertaken to detect dynamic cardiac changes.

\section{CONCLUSION}

Organophosphorus poisoning can cause severe cardiac complications within few hours of exposure. Myocardial infarction occurs as a complication during the early phases of poisoning, but it also has chances of occurring during the recovery phases. Thus, during the management of organophosphorus compound poisoning, intensive cardiac monitoring should be considered.

\section{ACKNOWLEDGEMENT}

We acknowledge the contribution of our university and department for the unending support.

Conflict of Interest: There is no conflict of Interest

Source of Funding: No Source of Funding

Authors Contribution: This is a collaborative work among both authors. Gautam Archana, Patil Vijaysinh, Rayannavar Nikhilesh and Goel Himalaya performed the statistical analysis, wrote the protocol, and wrote the first draft of the manuscript. Bhaleghare Sakshi, Bammidi Rohit managed the literature searches. All the authors read and approved the final manuscript.

\section{REFERENCES}

1. Akhtar MS, Rehman AU, Akbar K, Hussain M, Atif MA, Hussain MS. Complications of organophosphorus poisoning. Prof. Med. J. 2020 Oct 10;27(10):2149-53.

2. Joshi P, Manoria P, Joseph D, Gandhi Z. Acute myocardial infarction: Can it be a complication of acute organophosphorus compound poisoning?. J Postg Med. 2013 Apr 1;59(2):142.

3. Knotts RJ, Wilson JM, Kim E, Huang HD, Birnbaum Y. Diffuse ST depression with ST elevation in aVR: Is this pattern specific for global ischemia due to left main coronary artery disease? J Electroc. 2013 May 1;46(3):240-8.

4. Anand S, Singh S, Nahar Saikia U, Bhalla A, Paul Sharma Y, Singh D. Cardiac abnormalities in acute organophosphate poisoning. Clin Toxic. 2009 Mar 1;47(3):230-5.

5. Ludomirsky A, Klein HO, Sarelli P, Becker B, Hoffman S, Taitelman U, Barzilai J, Lang R, David D, DiSegni E, Kaplinsky E. QT prolongation and polymorphous ("torsade de pointes") ventricular arrhythmias associated with organophosphorus insecticide poisoning. Am J Cardiol. 1982 May 1; 49(7):1654-8.

6. Horio Y, Yasue H, Okumura K, Takaoka K, Matsuyama K, Goto $\mathrm{K}$, Minoda K. Effects of intracoronary injection of acetylcholine on coronary arterial hemodynamics and diameter. Am J Cardiol. 1988 Nov 1;62(13):887-91.

7. Yasue H, Touyama M, Shimamoto M, Kato H, Tanaka S, Akiyama F. Role of the autonomic nervous system in the pathogenesis of Prinzmetal's variant form of angina. Circulation. 1974 Sep;50(3):534-9.

8. Karasu-Minareci E, Gunay N, Minareci K, Sadan G, Ozbey G. What may happen after an organophosphate exposure: acute myocardial infarction. J Forensic Leg Med. 012 Feb 1;19(2):946. 
9. Gázquez V, Dalmau G, Gaig P, Gómez C, Navarro S, Mercé J. Kounis syndrome: report of 5 cases. J Investig Allergol Clin Immunol. 2010 Jan 1;20(2):162-5.

10. Anand S, Singh S, Nahar Saikia U, Bhalla A, Paul Sharma Y, Singh D. Cardiac abnormalities in acute organophosphate poisoning. Clin. Toxicol.. 2009 Mar 1;47(3):230-5.
11. Eddleston M, Chowdhury FR. Pharmacological treatment of organophosphorus insecticide poisoning: the old and the (possible) new. Br J Clin. Pharmacol. 2016 Mar; 81(3):462-70. 